\title{
Fertilidade de solo e viabilidade técnica - econômica da agricultura de precisão na região das Missões - RS
}

Soil fertility and technical fesiability -economics of precision agriculture in the region of Missions - RS

Flavio André Schadeck ${ }^{1}$

Claire DelfiniViana Cardoso ${ }^{1}$

${ }^{1}$ Universidade federal de Santa Maria ( UFSM ), Santa Maria RS, Brasil.

flavioas@via-rs.net, cdvcardoso@gmail.com

Recebido em 10/07/2015 - Aceito em 09/12/2016

Received on 10/07/2015 - Accepted on 09/12/2016

RESUMO-Este trabalho apresenta um estudo que foi realizado em uma área comercial de produção de grãos, no Município de Santo Ângelo-RS. Com a fertilidade do nutriente fósforo ( P ) já construída. Com o objetivo de verificar se o uso de ferramentas de Agricultura de Precisão ( AP ), pela aplicação de correção de fertilizantes a lanço e a taxa variada apresenta um aumento dos teores de fertilidade de solo, bem como as produtividades de soja e trigo ao longo de três anos subseqüentes e sua viabilidade técnica e econômica. Obteve-se uma redução de $43 \%$ no uso de calcário dolomítico e um aumento de produtividade de soja e trigo entre 19 e $28 \%$. O estudo mostrou um retorno econômico ao produtor de $22 \%$ comparado a uma área testemunha sem AP. Esperava-se um aumento nos teores de potássio na reamostragem mas não foi encontrado, levantando a hipótese de se fazer uma adubação de manutenção na cultura ao invés de se fazer um correção de solo.

Palavras-chave:Taxa variada.Produtividade de Grãos. Teores de Nutrientes do Solo. Saturação de Bases.

ABSTRACT - This paper presents a study that was conducted in a commercial area of grain production in the municipality of Santo Ângelo-RS.With a fertility for the nutrient phosphorus ( P ) already built.Thisstudy aimed todetermine whether useofprecision agriculturetools,by applyingfertilizerscorrectionbroadcasted withthevariable rateshows an increaseinsoil fertilitylevels, and to verifythe yield of soybeanand wheatoverthree yearssubsequentandits technical and economicviability.Obtained was a43\% reductionin the useof limeand an increase insoybean and wheatproductivitybetween 19 and $28 \%$. The study showedan economic returnto the producerof $22 \%$ compared to acontrol areawithoutPrecision Agriculture.It was expectedan increasein the potassium concentrationin theresamplingbut not found, raising the possibilityof doinga maintenancefertilization oncropinsteadof making asoil amendment.

Keywords: Variable Rate. Soil Grain Yield.Nutrient Levels. Base Saturation.

\section{INTRODUÇÃO}

A atividade agrícola brasileira vem crescendo em ritmos cada vez maiores, atendendo a necessidade de um aumento da demanda por alimentos devido a fatores tais como a elevação da renda de determinadas camadas da população mundial principalmente em países em desenvolvimento, acarretando um aumento significativo na procura por estes.

Muteia (2010) relata dados da Organização das Nações Unidas para Alimentação e Agricultura (FAO), que em 2010 a produção de cereais caiu 1,1\%, diante de um aumento de $1,9 \%$ na sua utilização. A arrancada econômica dos países emergentes registrada na última década resultou no aumento do consumo de produtos da agropecuária.

Segundo Carvalho (2011), as estimativas da FAO e da Organização para a Cooperação e Desenvolvimento Econômico (OCDE) mostram que a população brasileira poderá crescer $40 \%$ nos próximos 50 anos, a população mundial poderá chegar a 8,3 bilhões de habitantes em 2030. Considerando a área disponível para produção de alimentos e o numero de habitantes, percebe-se que cada vez mais a área agricultável/habitante irá diminuir mostrando no contexto atual que o aumento da produtividade será fundamental para atender a demanda mundial por alimentos.

As oscilações na produção de alimentos podem comprometer o suprimento destes, paralelamente ao crescimento da população ao ritmo de quase $1 \%$ ao ano, observa-se a importância de avaliar novas tecnologias, que tem sido colocadas a disposição dos produtores dentre outras podemos citar: Agroquímicos, Biotecnologia, Equipamentos de Irrigação e a Agricultura de Precisão.

Diante das mudanças climáticas que estão ocorrendo fica evidente a grande necessidade dos produtores agrícolas brasileiros, aqui em específico os 
produtores da Região das Missões, buscarem recursos, seja através das novas tecnologias para garantir sua rentabilidade e consequentemente sua permanência na atividade, ou mesmo a manutenção de práticas adotadas e conhecidas e que permitem uma reavaliação dos resultados obtidos.

Dentro deste contexto, um conjunto de técnicas que vem sendo adotadas e surtindo efeitos positivos em produtividade e reduzindo custo e impactos ambientais é a Agricultura de Precisão ( AP ) para auxiliar o produtor na escolha de melhores estratégias de manejo, permitindo identificar a variabilidade presente na áreas e, a partir disso, averiguar os fatores limitantes, propondo alternativas de manejo diferenciado de acordo com as necessidades de cada zona de manejo PES et al (2006).

\section{MANEJO DO SOLO}

O manejo do solo consiste em um conjunto de operações e decisões sobre a maneira como se trabalha o solo, tais como aplicações de defensivos e nutrientes, escolha de culturas, sistema de plantio e outras mais. Todas as decisões em relação à forma, técnica e sistema que se trabalha o solo estão interligados. Cada operação agrícola influencia o sistema, contribuindo ou prejudicando as demais operações em um ciclo dinâmico e subsequente. Devido a esses fatores destacamos o manejo de solo como algo de extrema importância para o entendimento dos estudos que vamos abordar neste trabalho.

Segundo Amado \& Santi (2007), o manejo racional do solo pode ser considerado a base de sustentação dos sistemas agrícolas. Sendo assim, avanços tecnológicos tem possibilitado o aprimoramento do manejo do solo. Historicamente, a insustentabilidade do preparo convencional, no Sul do Brasil, estimulou os agricultores a adotarem o sistema plantio direto. Assim como o sistema de plantio direto, outras tecnologias transformaram profundamente a agricultura brasileira nas últimas décadas. $\mathrm{O}$ melhoramento genético ofertando cultivares adaptadas à diferentes zonas agroclimáticas no país, a biotecnologia, a irrigação por pivô central, o gerenciamento da unidade da produção e a busca de eficiência em todos os processos dotaram de competividade a agricultura nacional, tornando-a capaz de adaptar-se a globalização e de competir no mercado internacional. Nesse cenário, o monitoramento da variabilidade espacial das características do solo e seus efeitos no desenvolvimento e na produtividade das culturas passou a ser possível.

Dentro do contexto da globalização da economia e a competitividade de preço dos produtos agrícolas, surgiu a necessidade de se obter níveis de competitividade internacionais. Além disto, a busca pela conservação dos recursos naturais, impõe à atividade agrícola novos métodos e técnicas de produção, aliados à eficiência e maior controle dos resultados obtidos nocampo, em relação ao que se pratica hoje Vargas (2003).

Outro aspecto que devemos considerar no estudo do manejo do solo é seu grau de resistência à penetração, que vem a ser o nível de compactação do solo. Em áreas manejadas sob sistema de plantio direto, tem sido observada a formação de uma camada de solo mais compactada a 8-20 $\mathrm{cm}$ de profundidade (Genro Junior et al., 2009). Em algumas situações, o grau de compactação do solo dessa camada atinge valores limitantes à produtividade das culturas FRANCHINI et al. ( 2009).

Estudos direcionados aos parâmetros edáficos indicam a relação direta da compactação coma redução da produtividade no sistema de plantio direto na palha. Neste mesmo sistema tem sido observado aumento de densidade de solo superficial, tendo como consequência maior resistência à penetração (RP) ou índice de cone. VIACHESLAV \& MOLIN (2006).

Segundo Molin (2002), a principais causas da compactação estão relacionadas aos sistemas de manejo adotados, onde a perda da matéria orgânica causa o adensamento do solo, influenciando diretamente em sua resistência à penetração, como também o uso de máquinas e implementos pesados acaba agravando a condição de compactação dos solos, principalmente devido as condições de trabalho inadequadas, como excesso de umidade.

A exigência de uma maior produtividade vem gerando um número cada vez maior de operações nas lavouras, destacando uma tendência de maior compactação de solo. Debiasi (2012) conclui em seu estudo que a variabilidade espacial da resistência a penetração é influenciada pela profundidade e pela intensidade de amostragem. E que a redução do número de pontos amostrais promove maior erro na estimativa de resistência a penetração por krigagem, o que é mais evidente na camada de maior interesse para avaliação da compactação de 10 a $20 \mathrm{~cm}$.

Analisando os vários estudos que vem sendo feitos por instituições de pesquisa ligadas a agricultura pode-se verificar que no quesito variabilidade espacial e temporal existem uma série de fatores interferindo sobre a dinâmica de elementos nutricionais das plantas, o que nos leva a concluir que o grau de precisão de um estudo será maior quanto maiores forem as variáveis estudadas durante o processo de realização do trabalho.

\subsection{Agricultura de Precisão (AP)}

Segundo Blackmore et al (1994) relata que a Agricultura de Precisão é um termo que descreve a meta de aumentar a eficiência do manejo da agricultura, sendo uma tecnologia em desenvolvimento, que modifica técnicas existentes e incorpora novas ferramentas para o administrador utilizar. O mesmo autor considera que o manejo da variabilidade é chave para o uso efetivo da tecnologia da agricultura de precisão.

Para Lemainski (2007), a AP trata-se de uma filosofia de gerenciamento agrícola que parte de informações precisas e completa-se com as decisões, levando em conta o fato de que cada unidade agrícola possui condições diferentes.

Campo (2000) considera que Agricultura de precisão é o conjunto de técnicas e procedimentos que permite 
conhecer, localizar geograficamente e delimitar áreas de diferente produtividade, através do emprego da informática, programas específicos, sensores, controladores de máquinas e sistema de posicionamento global (GPS). Até o presente, a agricultura de precisão não pode ser completamente definida porque estamos todos procurando por seus ingredientes uma combinação adequada de instrumentos, medidas e métodos para gerenciar quantitativamente as áreas produtivas. Nielsen et al (1996)

\subsection{Uso de Tecnologias de AP}

O cenário que observamos hoje mostra uma tendência forte pela busca de uma maior eficiência dos recursos ambientais, humanos e técnicos, paralelamente um menor impacto ambiental. Sob este ponto de vista a adoção de técnicas e tecnologias com maior precisão para o manejo adequado do ecossistema pode reduzir o impacto ambiental de maneira significativa, a partir de uma aplicação eficiente de insumos. Neste caminho os benefícios econômicos e ambientais do uso de tecnologias de agricultura de precisão, usando a variabilidade espacial e temporal necessitam de mais estudos.

Em estudos agronômicos envolvendo o sistema soloágua-planta deve-se considerar a variabilidade espacial e temporal dos atributos do solo, pois os fatores e processos de formação do solo (clima, relevo, tempo, ação de organismos e material de origem), que atuaram ao longo do tempo imprimiram-lhe heterogeneidade, que somado ao manejo realizado pelo homem, acentuaram a variabilidade dos atributos do solo ALBUQUERQUE et al (1996).

A Agricultura de precisão tem se mostrado uma ferramenta importante, principalmente, para a caracterização da variabilidade espacial de atributos de solo e das culturas Bellé (2009). Mostrando que a AP não se limite apenas as correções de fertilizantes com taxa variável, este mesmo autor com relação à medição da umidade do solo com uso de dados de satélites obteve resultados com uma precisão de $95 \%$.

Outra ferramenta usada para o mapeamento da fertilidade de solo em AP são os mapas de produtividade. De acordo com Molin (2007), o mapa de produtividade é a informação mais completa para se visualizar na variabilidade espacial das lavouras. Sendo assim, a determinação da variabilidade é mais facilmente visualizada a partir da produtividade expressa, podendo assim, ser associado com outros fatores que podem estar interferindo a expressão do potencial de rendimento da cultura. Este mesmo autor relata que a variabilidade que se expressa na colheita, em termos de diferenças de produtividade ao longo da lavoura, tem causas variadas e de maneira alguma pode ser atribuída a um ou outro fator isoladamente.

Segundo Amado \&Santi (2007) os mapas de produtividade permitem que o produtor faça comparações de variedades, fertilizantes, fungicidas, inseticidas em sua própria área. De maneira que os mapas de produtividade podem ser uma ferramenta para comprovar a eficiência de novas tecnologias.

\subsection{Viabilidade Técnica Econômica da AP}

Amado (2007) comenta a racionalização no uso de insumos, no caso de calcário de $25 \%$ e potássio de $15 \%$ e incrementos de produtividade entre $5 \%$ e $10 \%$ com uso da AP. Ainda, Fiorin et al (2011) observa sobre o retorno econômico ao produtor variando de $9,2 \%$ a $13,7 \%$ com o uso de técnicas em Agricultura de Precisão.

Costa (2011), em estudo sobre os impactos econômicos da Agricultura de Precisão comenta que há necessidade de aumento de produtividade das culturas de grande influência econômica como cana-de-açucar, soja e milho, ao qual somente com a redução de uso de fertilizantes não obteria impacto positivo, somente redução de impactos ambientais.

Estudo feito em usinas de cana-de-açucar e álcool por Menegathi e Molin (2006), obtiveram redução nos gastos com calcário e fósforo na ordem de $15 \%$ e $36 \%$ e aumento de produtividade de $9 \%$ e $4,5 \%$ em relação a média.

Magalhães (2013) estudando o efeito da Agricultura de Precisão em pomares de laranjeiras obteve redução dos insumos entre $30 \%$ e $40 \%$, enquanto o aumento da produtividade ficou em $10 \%$ quando houve, isto é, o crescimento na produção não foi constante, mas pôde ser observado em alguns momentos. Onde também, foi possível melhorar alguns parâmetros da fertilidade do solo como os níveis de potássio e saturação de bases na área toda.

Sendo assim, constata-se que existem no momento uma série de ferramentas de agricultura de precisão, todas elas evidenciando benefícios em diferentes culturas e em diferentes mecanismos do processo da agricultura, mas que necessitam diferentes testes em variadas situações de uma propriedade rural, para ser possível comprovar a sua validade. As aplicações de fertilizantes a taxa variada e a lanço, são apenas uma parte deste conjunto de ferramentas disponíveis.

\section{3.ÁREA DO TRABALHO}

O estudo foi realizado em uma área comercial no município de Santo Ângelo, pertencente à região Noroeste do Rio Grande do sul, conhecida com Missões como segue na Figura 1. A área de 115 ha, está situada entre as coordenadas geográficas de latitude $28^{\circ} 27^{\prime} 86^{\prime \prime}$ S a $28^{\circ} 28^{\prime} 47^{\prime \prime} \mathrm{S}$, e longitude $54^{\circ} 19^{\prime} 69^{\prime \prime}$ W a $54^{\circ} 20^{\prime} 44^{\prime \prime} \mathrm{W}$, com altitude aproximadamente de 286 metros pelo sistema geodésico de referência SIRGAS2000, como mostrada na Figura 2.

O clima do município, segundo a classificação de Köppen-Geiger, é do tipo Cfa - Subtropical úmido, com precipitação variando de 1500 a 2600 milímetros anuais. A temperatura média é próxima de $20,2^{\circ} \mathrm{C}$, com máximas no verão podendo atingir $41^{\circ} \mathrm{C}$ e mínimas no inverno atingindo valores inferiores a $0^{\circ} \mathrm{C}$ ( MORENO, 1961). 
O relevo da área em estudo é ondulado; o solo é classificado como Latossolo Vermelho Distroférrico típico, com predominância de teores de argila entre 50 a $60 \%$. Os teores de matéria orgânica encontram-se predominantemente entre 3 a 5\%. (STRECK et al. 2008)

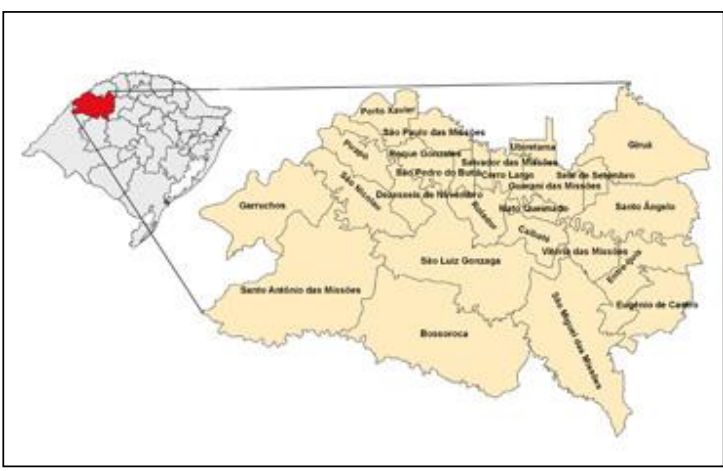

Figura 1- Quadro destacando a Região das Missões no Rio Grande do Sul.

Fonte: www.jom.com.br

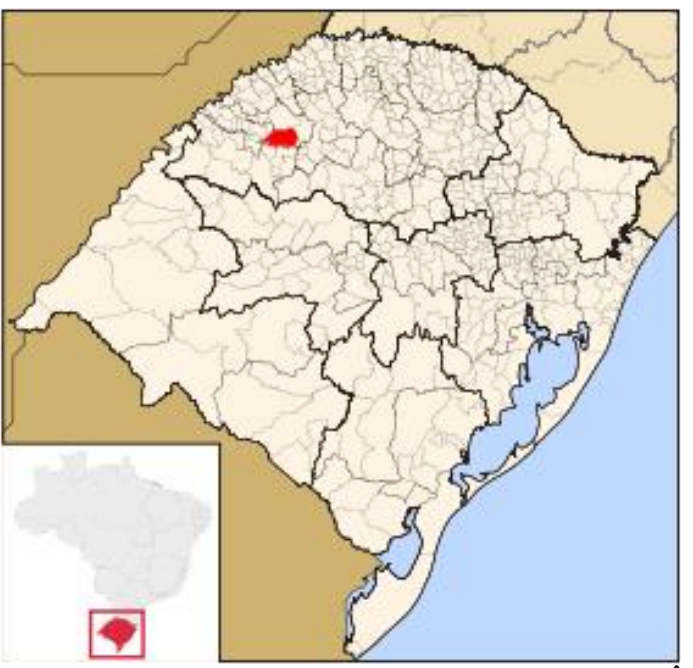

Figura 2 - Quadro destacando o Município de Santo Ângelo no Estado do Rio Grande do Sul.

Fonte: www.mfrural.com.br

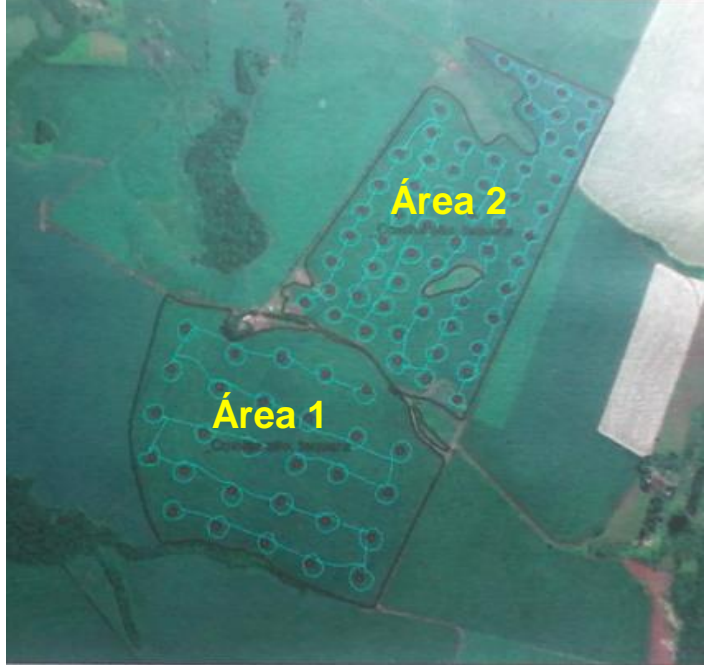

Figura 3 - Imagem da área de estudo - Coxilha do Alto (58 ha)- (Área 1) da figura e a Coxilha da Taquaras (57ha) - (Área 2) usada como testemunha, Município de Santo Ângelo - RS. Fonte: Arquivo do autor

\section{METODOLOGIA}

O manejo e condução do sistema de AP foi iniciado em junho de 2011, em uma área comercial de 58 ha. Foi realizada amostragem georreferenciada do solo; interpretação dos atributos químicos; elaboração de mapas de condições químicas; recomendações e aplicações de corretivos e fertilizantes a taxa variada. A área vem sendo manejada com sistema de plantio direto desde o ano de 1997, portanto em um sistema já consolidado. No período estudado de junho de 2011 a junho de 2014, a sequência de culturas utilizada foi: aveia cobertura/soja, trigo/soja e trigo/soja. E outra área ao lado de 57 ha, utilizada como testemunha para o devido acompanhamento do experimento, realizado com a sequência de culturas de trigo/soja, aveia cobertura/soja e trigo/soja.

A amostragem do solo foi realizada em 05/06/2011 e a reamostragem em 23/06/2014, utilizando uma malha quadricular regular de $200 \times 200 \mathrm{~m}$, totalizando 28 pontos amostrais. Cada amostra foi composta por doze subamostras, coletadas em raio aproximado de $10 \mathrm{~m}$ ao redor do ponto central georreferenciado. A profundidade de coleta foi de 0 a $15 \mathrm{~cm}$, utilizando como instrumento amostrador quadriciclo com trado. As amostras foram encaminhadas ao laboratório da empresa Base AP em Silveira Martins, RS. Em todas amostras foram realizadas análises completas, segundo as metodologias de análise descritas por Tedesco (1995), com controle de qualidade pela Rede Oficial de Laboratórios de Análise de Solos ( ROLAS ). Na reamostragem foram determinados os mesmos pontos e parâmetros químicos propostos para análises da condição inicial.

O manejo da fertilidade, envolvendo a correção da acidez e a adubação de correção do potássio ( $\mathrm{K}$ ) foram determinadas para elevar a saturação por bases a $80 \%$ e o $\mathrm{K}$ a $2 \%$ da CTC. Nos 58 ha da área em teste foram utilizados 65,5 toneladas de calcário dolomítico em 55,2 ha como visto na Figura 4; e 2,9 toneladas de cloreto de potássio em 12,4 ha na Figura 5, aplicados a taxa variada 
em superfície. Utilizou-se equipamento da Marca Jan, Modelo 12000 que possui controlador de vazão de taxa variada, este comprado em parceria com outro produtor, no mês de maio de 2011 .

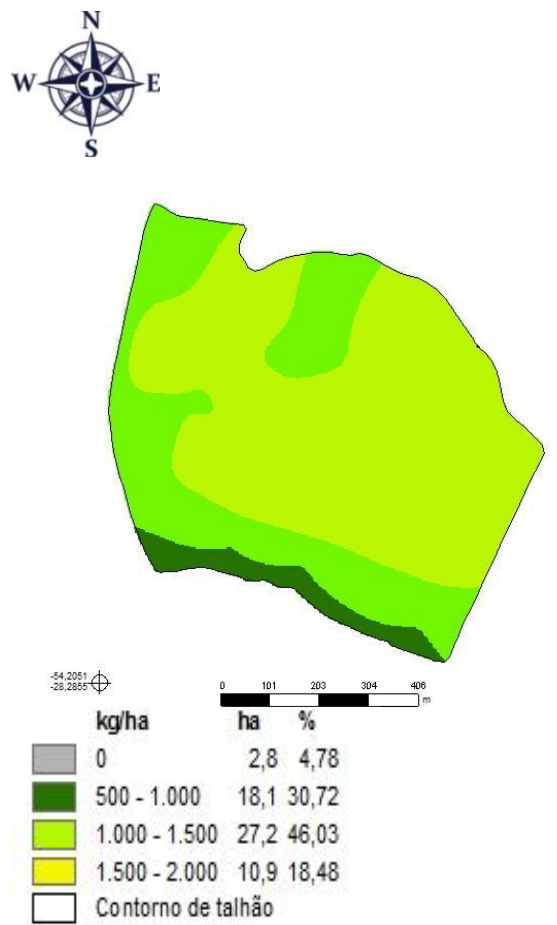

Figura 4 - Espacialização dos valores de Calcário Dolomítico $\mathrm{Kg} \mathrm{ha}^{-1}$ para elevação da saturação por bases a $80 \%$.

Fonte: Arquivo do autor
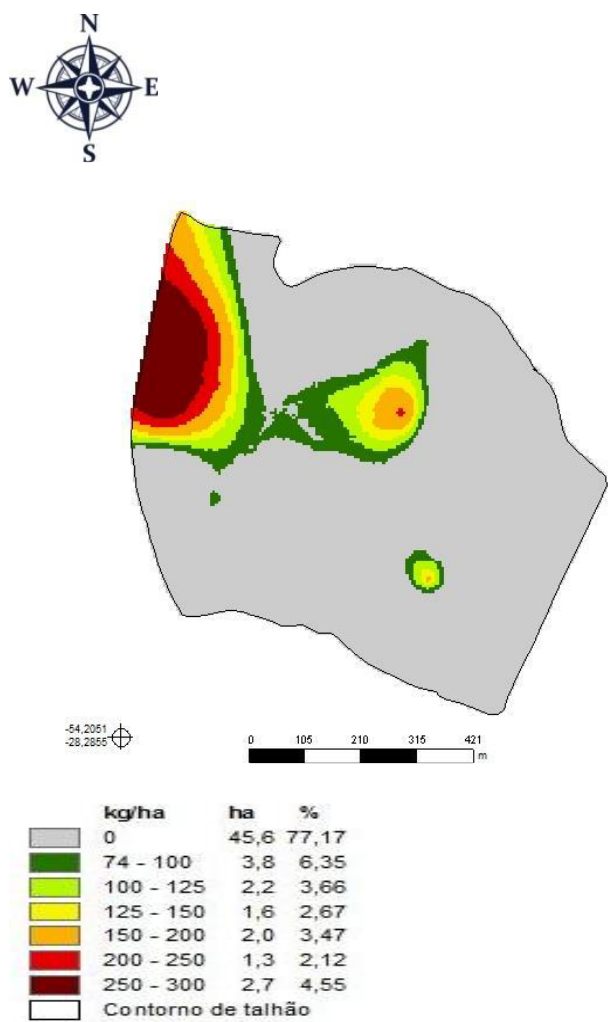

Figura 5 - Espacialização dos valores de cloreto de potássio $\mathrm{Kg}$ ha ${ }^{-1}$ para correção de $\mathrm{K}$ a $2 \%$ da CTC.

Fonte: Arquivo do autor
Quanto ao fósforo ( $\mathrm{P}$ ), optou-se em não fazer a correção utilizando o critério de que $96 \%$ da área encontra-se com teores acima de $15 \mathrm{mg} \mathrm{dm}^{-1}$ e apenas $4 \%$ da área entre a faixa de 12 a $15 \mathrm{mg} \mathrm{dm}^{-1}$, considerando que $100 \%$ da área estava com níveis altos e só necessitando de adubações de manutenção. Tratandose de uma situação diferenciada da maioria das propriedades dos produtores, ao qual se tem uma fertilidade para o fósforo $(\mathrm{P})$ já construída.

Um fator que prejudicou a uniformidade de distribuição a lanço dos fertilizantes foi o fato da cultura da aveia preta estar em pleno florescimento, com uma altura de plantas acima dos pratos distribuidores do equipamento, de modo que trajeto de uma parte dos grânulos dos fertilizantes lançados foi obstruída mudando sua trajetória concentrando mais os grânulos em algumas partes e em outras menos.

As adubações de manutenção foram realizadas durante o plantio das culturas, na linha no mesmo padrão que comumente se usava nos anos anteriores, na cultura da soja $200 \mathrm{Kg} \mathrm{ha}^{-1}$ da fórmula 022323 , na cultura do trigo com o adubo DAP $200 \mathrm{Kg}^{-1}$ (18 46 00) no plantio e $100 \mathrm{Kg}^{-1}$ de uréia cloretada na fórmula (30 00 20) em cobertura e na cultura da aveia-preta $150 \mathrm{Kg}$ ha $^{-1}$, da fórmula (05 2020 ) para cobertura de solo.

A adubação de manutenção das culturas de soja e trigo foram realizadas considerando as expectativas de produtividades de 3,0 tha ${ }^{-1}$ de grãos, respectivamente.

$\mathrm{Na}$ área testemunha de 57 ha ao lado, foi realizada a correção do $\mathrm{pH}$ com 143 toneladas $\left(2\right.$ ton ha $\left.{ }^{-1}\right)$ de Calcário Dolomítico a lanço em dose fixa no ano 2012 sobre aveia preta.

Devido ao fato de no período 2011/2012 ter ocorrido uma estiagem de aproximadamente cinco meses, fato esse que comprometeu a avaliação das produtividades, sendo que estas avaliações foram realizadas a partir do ano 2012/2013. A semeadura da cultura da soja ocorreu no período compreendido dos dias 05 a 23 novembro, exceto para a área testemunha plantada até 05/12/13, devido a dificuldades de plantio na palhada da aveia preta. Para o trigo, o plantio ocorreu durante os dias 01 a 15 de junho. A aveia preta não foi colhida, usada somente com objetivo de cobertura de solo.

A avaliação de produtividade foi feita pela média dos talhões de 58 ha e 57 ha com base no peso liquido entregue a empresas de recebimentos de grãos da cidade de Santo Ângelo e os custos pelos valores pagos pelos fertilizantes utilizados.

$\mathrm{O}$ balanço nutricional de fósforo e potássio foi realizado somando todos os $\mathrm{Kg}^{-1}$ de $\mathrm{P}_{2} \mathrm{O}_{5}$ e $\mathrm{K}_{2} \mathrm{O}$ de todas as adições representadas pelas adubações na linha desde a adubação na linha para aveia de cobertura no ano de 2011 até a aveia para cobertura no ano de 2014 e a correção do potássio realizada com a aplicação a lanço de $4900 \mathrm{Kg}$ de cloreto de potássio ( $\begin{array}{lll}00 & 00 & 60\end{array}$ ) representado pelo valor total em números positivos no Quadro 4 . Considerando que para cada tonelada de soja 
colhida foram exportados $14 \mathrm{Kg}$ de $\mathrm{P}_{2} \mathrm{O}_{5}$ e $20 \mathrm{Kg}$ de $\mathrm{K}$ ${ }_{2} \mathrm{O}$ e de trigo $8 \mathrm{Kg}$ de $\mathrm{P}_{2} \mathrm{O}_{5}$ e $6 \mathrm{Kg}$ de $\mathrm{K}_{2} \mathrm{O}$. Foi realizado o balanço dos valores de $\mathrm{P}_{2} \mathrm{O}_{5}$ e $\mathrm{K}_{2} \mathrm{O}$ em $\mathrm{Kg}$ exportados através das produções colhidas de soja e trigo de 2011 a 2014, representado pelo valor total em números negativos. Sendo o saldo, o resultado do valor total das adições realizadas em valores positivos subtraíndo-se o valor das exportações pelas colheitas dos grãos, em valores negativos.

Os mapas que seguem nas figuras foram elaborados usando interpolação por Krigagem, o software utilizado foi o SGIS da Topcon, ferramenta utilizada para criar os mapas de taxa variável de nutrientes, também pode fornecer dados de colheita como massa e volume de safra e teor de umidade.

A recomendação da correção da acidez foi feita utilizando a equação:

$\mathrm{NC}(\mathrm{t} / \mathrm{ha})=\mathrm{CTC} .(V 2-V 1) / 100 \cdot 1,42 \cdot 0,5$

No qual a NC é necessidade de calcário toneladas ha

${ }^{-1}$ com Poder Relativo de Neutralização Total (PRNT) de $100 \%$, V2 é a percentagem de saturação desejada, V1 é a percentagem de saturação por bases encontrada na análise do solo, que teve como meta a elevação da saturação de bases para $80 \%$, multiplicado por 1,42 para corrigir o ( PRNT ) de $70 \%$ para $100 \%$ e a multiplicação por 0,5 com objetivo de usar apenas metade da dose da fórmula.

Em relação aos custos de implantação do sistema AP foram feitas pela empresa Base AP, todos os serviços de coleta, análise e confecção de mapas de fertilidade ao custo de R \$ 50,00/ha, resultando nos 58 ha um total de R $\$$ 2.900,00. Os gastos com aplicação de três toneladas de cloreto de potássio foram de $\mathrm{R} \$ 2.940,00$, sendo $\mathrm{R} \$$ 1.014,00/tonelada. A economia de 50,5 toneladas de calcário dolomítico foi equivalente a $\mathrm{R} \$ 4.040,00$.

A despesa com a compra de um equipamento de aplicação a taxa variada teve o custo de $\mathrm{R} \$ 15.590,00 / 3$ anos, parcelado em 10 anos, ao juro de 6,5\% ao ano. A análise de custo realizada, ao qual foram feitos cálculos permitiu chegar-se a conclusão de que o gasto no aluguel de um equipamento terceirizado poderia ser usado para pagar o financiamento de um equipamento novo comprado em parceria com outro produtor. Foram feitos nestes dois anos 302 ha, resultando em um custo de $\mathrm{R} \$$ $52,00 / \mathrm{ha}$. Para os valores da receita bruta/ha/anual foram obtidos usando como referência valores do preço de uma saca de $60 / \mathrm{Kg}$ de soja a $\mathrm{R} \$ 50,00$ e o trigo a 25,00 .

\section{RESULTADOS E DISCUSSÃO}

Verificou-se na safra de soja de 2012/13, que embora a área onde aplicou-se técnicas de AP ficou com uma população de plantas de 178000 plantas/ha devido a problemas de germinação e vigor, tenha representado uma diferença de $33 \%$ menos plantas/ha que a área testemunha que ficou com uma população de 266000 plantas/ha, ainda produziu 4,2\% menos que esta. As plantas da área com AP, mostraram-se mais verdes e mais resistentes durante o período de estiagem, o que confirmou-se durante a colheita com uma pequena diferença entre a área de teste e testemunha, demonstrando uma boa capacidade de recuperação.

Analisando os resultados obtidos na análise estatística descritiva dos valores de $\mathrm{pH}$ na Tabela 1 que segue, verificou-se que as medidas de posição média, mediana e máxima tiveram uma redução dos valores na reamostragem e que a medida de mínima teve leve aumento, demonstrando a ação do processo de acidificação do solo pelo uso das adubações de manutenção e cobertura durante este período dos três anos. Obteve-se valores de desvio padrão e CV\% menores na reamostragem, mostrando que houve pequena redução da heterogeneidade da área em relação ao $\mathrm{pH}$ de solo como podemos observar na Figura 6.

Em relação ao teste de assimetria, ambas as amostragem mostraram-se dentro dos padrões de moderada, compreendidos na faixa de $0,15<\mathrm{AS}<1,00$. Como também para o teste de Shapiro-Wilk aos quais os valores mostraram-se significativos dentro de um padrão de distribuição normal.

A curtose foi classificada como leptocúrtica, ou seja que a distribuição tem caudas pesadas, obtendo-se mais facilmente valores que se afastam da média a vários múltiplos do desvio padrão.

Tabela 1- Análise estatística descritiva dos teores de $\mathrm{pH}$ em água no solo coletados nos anos de 2011 e 2014, na profundidade de 0 a $15 \mathrm{~cm}$. Santo Ângelo - RS, 2014.

\begin{tabular}{lll}
\hline $\begin{array}{l}\text { Parâmetros } \\
\text { Estatísticos }\end{array}$ & $\mathbf{2 0 1 1}$ & $\mathbf{2 0 1 4}$ \\
\hline $\begin{array}{l}\text { Número de } \\
\text { Observações } \\
\text { Mínimo }\end{array}$ & 28 & 28 \\
Média & 5,30 & 5,33 \\
Mediana & 5,72 & 5,64 \\
$\quad$ Máximo & 5,70 & 5,64 \\
$\quad$ Desvio Padrão & 6,30 & 6,25 \\
$\quad \begin{array}{l}\text { Coeficiente de } \\
\text { Assimetria }\end{array}$ & 0,24 & 0,22 \\
$\quad \begin{array}{l}\text { Curtose } \\
\text { Teste Shapiro- }\end{array}$ & 4,22 & 3,90 \\
Wilk & 0,74 & 0,97 \\
\hline
\end{tabular}

Fonte: Arquivo do autor 


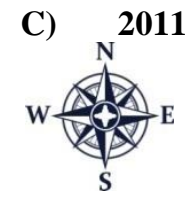

D) 2014
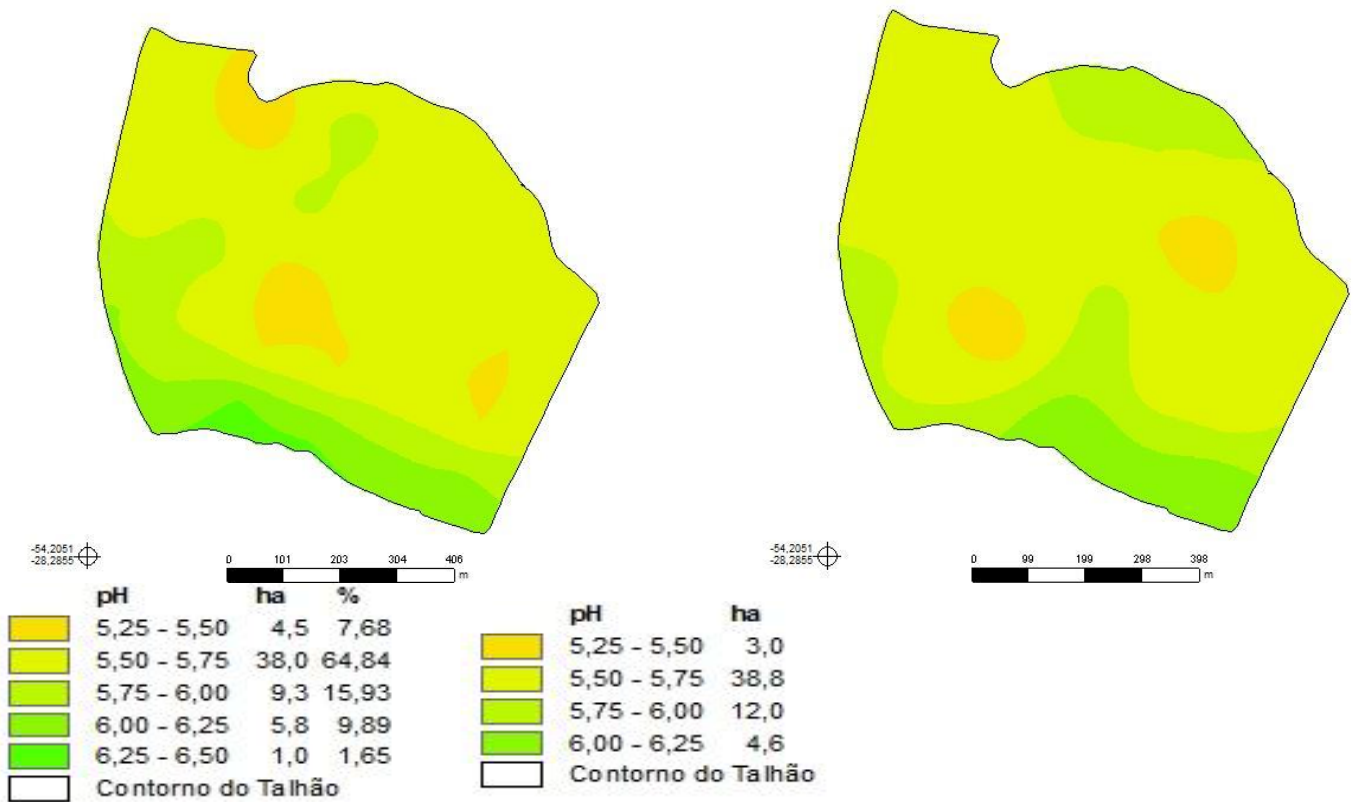

Figura 6 - Espacialização dos valores de pH em água, na profundidade de $0-15 \mathrm{~cm}$ ( C ) no momento da amostragem ( 2011 ) e (D) no momento da reamostragem (2014).

Fonte: BaseAP, 2014.

Analisando os resultados obtidos na análise estatística descritiva dos valores da saturação por bases como apresentado no Tabela 2, verificou-se que os valores das medidas de posição mínima, média e mediana foram levemente inferiores na reamostragem e levemente maiores para a medida de máxima. Para as medidas de desvio padrão e $\mathrm{CV} \%$ na reamostragem foram um pouco maiores, como podemos observar na Figura 7, que define na reamostragem, uma redução de 8,5 ha na faixa de saturação de bases de 70 a $80 \%$ e de 1,7 ha na faixa acima de $80 \%$, consequentemente um aumento da faixa de 60 a $70 \%$ de 16,18 ha.

Para a assimetria os valores encontraram-se na faixa de moderada entre $0,15<$ AS $<1,00$. Quanto ao teste $\mathrm{W}$ os valores das medidas mostraram-se não significativos, valores > 0,05, na qual a hipótese de distribuição normal é rejeitada, mostrando um comportamento aleatório.
Tabela 2 - Análise estatística dos valores da Saturação por bases no solo coletadas nos anos de 2011 e 2014, na profundidade de 0 a $15 \mathrm{~cm}$. Santo Ângelo-RS, 2014.

\begin{tabular}{lll}
\hline $\begin{array}{c}\text { Parâmetros } \\
\text { Estatísticos }\end{array}$ & $\mathbf{2 0 1 1}$ & $\mathbf{2 0 1 4}$ \\
\hline $\begin{array}{l}\text { Número de } \\
\text { Observações } \\
\quad \text { Mínimo }\end{array}$ & 28 & 28 \\
$\quad$ Média & 60,2 & 57,5 \\
$\quad$ Mediana & 69,31 & 67,43 \\
$\quad$ Máximo & 68,5 & 66,8 \\
$\quad \begin{array}{l}\text { Desvio Padrão } \\
\quad \text { Coeficiente de }\end{array}$ & 81,2 & 84,4 \\
variação ( CV \%) & 6,19 & 6,42 \\
$\quad$ Assimetria & 8,93 & 9,52 \\
$\quad$ Curtose & 0,53 & 0,89 \\
$\quad$ Teste Shapiro- & $-0,88$ & 0,56 \\
Wilk & 0,052 & 0,113 \\
\hline
\end{tabular}

Fonte: Arquivo do autor 
A) 2011
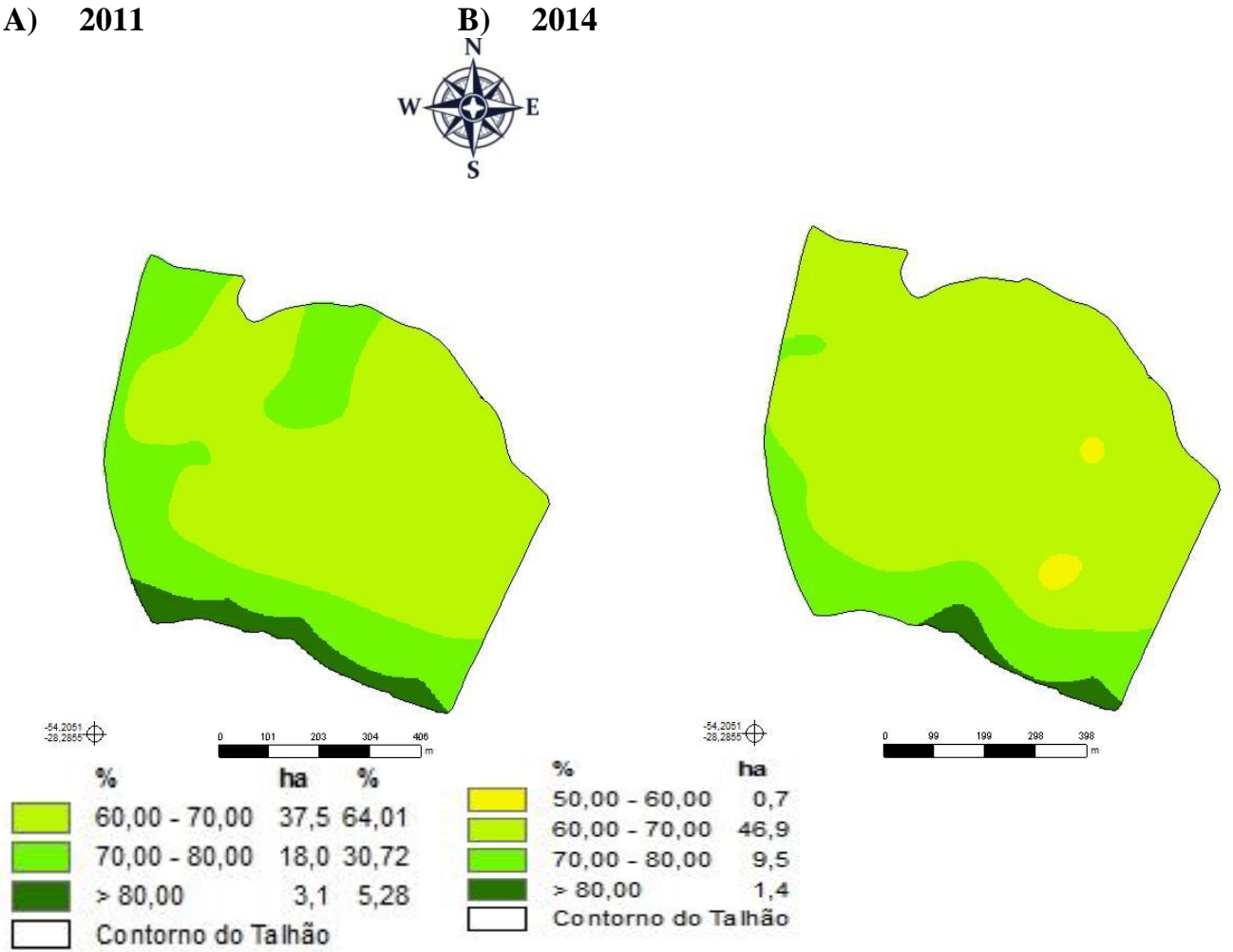

Figura 7 - Espacialização dos valores da saturação por bases, na profundidade de

$0-15 \mathrm{~cm}$ ( A ) no momento da amostragem ( 2011 ) e (B ) no momento da reamostragem ( 2014 ).

Fonte: BaseAP, 2014.

A recomendação da adubação de correção de potássio $(\mathrm{K})$ teve como meta a elevação dos teores para $4 \%$ da CTC. Para isso realizaram-se aplicações com cloreto de potássio a taxa variada em quantidades que variaram de 50 a $300 \mathrm{Kg} / \mathrm{ha}$, num total de $2900 \mathrm{Kg}$ na área das 58ha.

Analisando os resultados obtidos na análise estatística descritiva do teores de K ( Tabela 3 ) verificou-se que as medidas de posição mínima, média, mediana e máxima tiveram uma redução dos teores na reamostragem, sendo maiores para o Desvio Padrão. Com relação ao Coeficiente de Variação (CV\%) tanto na amostragem como na reamostragem, os valores ficaram na faixa média $(12<\mathrm{CV}<62 \%)$ e verificou-se um aumento do CV\% na reamostragem de 2014 como podemos visualizar na Figura 8.
Tabela 3 - Análise estatística descritiva dos teores de potássio no solo coletados nos anos de 2011 e 2014, na profundidade de 0 a $15 \mathrm{~cm}$. Santo Ângelo - RS, 2014.

\begin{tabular}{lll}
\hline $\begin{array}{l}\text { Parâmetros } \\
\text { Estatísticos }\end{array}$ & $\mathbf{2 0 1 1}$ & $\mathbf{2 0 1 4}$ \\
\hline Número de obs & 28 & 28 \\
Mínimo & 128,80 & 66,8 \\
Média & 165,51 & 159,06 \\
Mediana & 163,70 & 139,50 \\
Máximo & 207 & 180,9 \\
Desvio Padrão & 20,60 & 34,96 \\
CV ( \% ) & 12,45 & 26,64 \\
Assimetria & 0,67 & $-0,24$ \\
Curtose & $-0,82$ & $-1,25$ \\
T. Shapiro-Wilk & 0,09 & 0,58 \\
\hline
\end{tabular}

Fonte: Arquivo do Autor 
$\mathbf{E}$

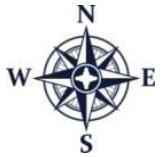

F)

2014

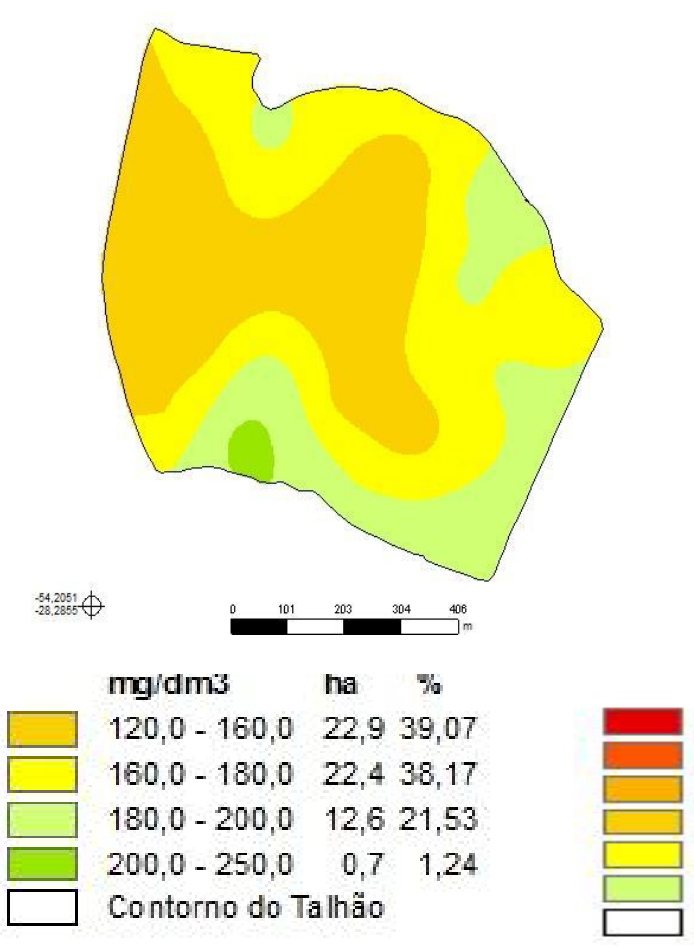

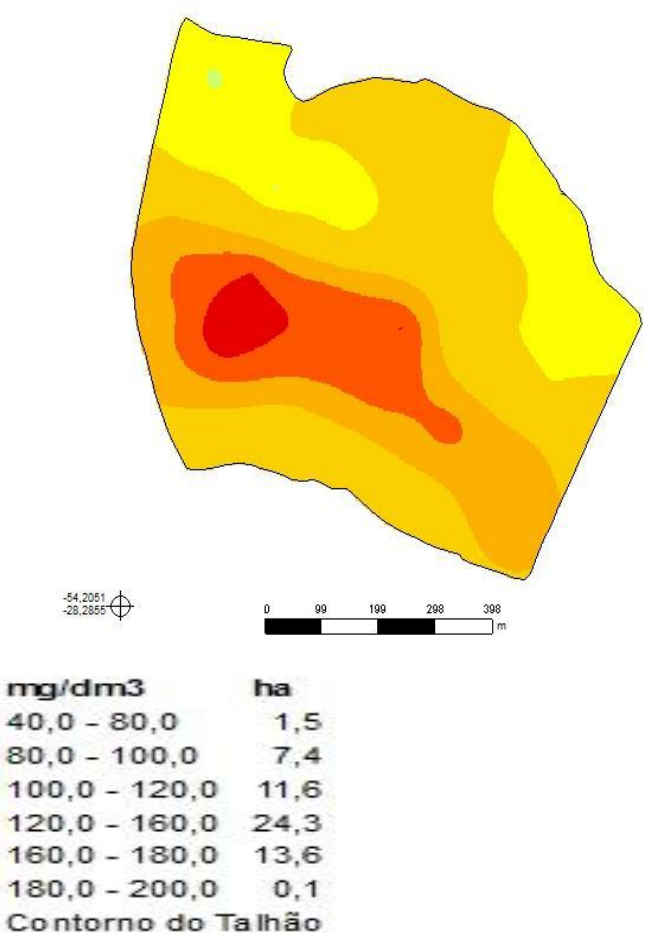

Figura 8 - Espacialização dos valores de potassio, na profundidade de 0 - $15 \mathrm{~cm}$ ( E ) no momento da amostragem ( 2011 ) e (F) no momento da reamostragem ( 2014 ).

Fonte: BaseAP, 2014

Esse aumento do CV\% do Potássio a lanço em taxa variada também foi encontrada por SANTI et al (2012) em trabalhos analisando solos coletados nos anos de 2008 e 2010.

Constatou-se uma maior heterogeneidade nos teores de $\mathrm{K}$ na reamostragem, o que nos leva a concluir, que outros fatores interagem na sua distribuição, mostrando que as aplicações de correção a taxa variada realizada tiveram um efeito residual menor que três anos. Também foi realizado um Balanço Nutricional como visto no Tabela 4, ao qual constatou-se que o saldo do balanço nutricional de $\mathrm{K} 2 \mathrm{O}$ foi de $108 \mathrm{Kg}$ positivo descartando a hipótese de que as exportações deste pudessem ser maiores que as manutenções.

Quanto a assimetria, verificamos que na amostragem os valores encontravam-se na faixa moderada $(0,15<$ AS $<1,00)$ e que na reamostragem passaram a faixa de fraco (AS $<1,00)$, mostrando maior tendência ao erro.
No teste de Shapiro-Wilk, tanto a amostragem quanto a reamostragem mostraram valores não significativos, apresentando um comportamento aleatório. A não normalidade dos dados é bastante freqüente em estudos que levam em consideração a posição geográfica e a dependência espacial dos dados. Cressie (1991 apud CORA \& BERALDO, 2006), afirma que a normalidade dos dados não é uma exigência da geoestatística, sendo conveniente apenas que a distribuição não apresente caudas muito alongadas, o que pode comprometer resultados.

Um outro fator que pode estar interagindo nos teores de potássio é o escoamento superficial, que pode estar sendo agravado pela compactação de solo que neste caso não foi avaliada. 
Tabela 4 - Balanço nutricional de fósforo e potássio das culturas em sucessão entre as adubações de manutenção e cobertura ( $\mathrm{Kg}$ ha de nutriente adicionado nas adubações de manutenção e a lanço ) e as exportações medidas pelos teores destes nutrientes exportados, representados em toneladas de grãos produzidos.

\begin{tabular}{|c|c|c|c|c|c|c|c|}
\hline \multirow[t]{2}{*}{ Ano } & \multirow[t]{2}{*}{ Cultura } & \multirow{2}{*}{$\begin{array}{l}\text { Adubação na linha Kg ha } \\
-1\end{array}$} & \multirow{2}{*}{$\begin{array}{l}\text { Produtividade } \\
\text { toneladas ha }^{-1}\end{array}$} & \multicolumn{2}{|c|}{ Adição } & \multicolumn{2}{|c|}{ Exportação } \\
\hline & & & & P2O5 & $K 20$ & P2O5 & K2O \\
\hline 2011 & Aveia & $150(022020)$ & Cobertura & 30 & 30 & 0 & 0 \\
\hline 2011 & Correção & $2900 \mathrm{Kg}(000060$ ) & & 0 & 30 & - & - \\
\hline 2011/12 & Soja & $200(022020)$ & 0,15 & 40 & 40 & 2,10 & 3 \\
\hline 2012 & Trigo & $\begin{array}{l}200(184600)+100(30 \\
0020)\end{array}$ & 2,49 & 66 & 20 & 29,40 & 17,64 \\
\hline 2012/13 & Soja & $200(022323)$ & 2,412 & 46 & 46 & 33,77 & 48,24 \\
\hline 2013 & Trigo & $\begin{array}{l}200(184600)+100(30 \\
0020)\end{array}$ & 3,96 & 66 & 20 & 39,60 & 23,76 \\
\hline 2013/14 & Soja & $150(022323)$ & 2,70 & 34,50 & 34,50 & 37,80 & 54 \\
\hline 2014 & Aveia & $150(022323)$ & Cobertura & 34,50 & 34,50 & 0 & 0 \\
\hline $\begin{array}{l}\text { Total } \\
\text { Saldo }\end{array}$ & & & & $\begin{array}{l}+317 \\
+174,50\end{array}$ & $\begin{array}{l}+225 \\
+108,50\end{array}$ & $-142,5$ & $-146,5$ \\
\hline
\end{tabular}

Fonte: Arquivo do Autor

Analisando a Tabela 4, observamos que o saldo final do balanço nutricional foi o resultado da soma de todas as adubações de manutenção desde o ano de 2011 a 2014, subtraindo a exportação de nutrientes no mesmo período. Os resultados mostraram que os valores ficaram positivos tanto para o $\mathrm{P} 2 \mathrm{O} 5$ como para o $\mathrm{K} 2 \mathrm{O}$.

Considerando que as amostras obtiveram como resultado da CTC, pH 7,0 valores entre 10,1 e 15 e adotando o padrão de teor do potássio segundo a Tabela 5 , podemos observar que na amostragem (2011), todas as amostras classificavam-se na faixa de interpretação como alto e que após a reamostragem (2014) passaram a se encontrar apenas $61 \%$ como alto e $39 \%$ como baixo a médio. Pela dinâmica do elemento Potássio no solo, observou-se que em certas partes da área ocorreu um decréscimo acentuado dos teores de Potássio, ao qual não era esperado.

Neste caso, podemos observar outros fatores interagindo na distribuição do $\mathrm{K}$, ao qual neste momento ainda não está esclarecido. E que analisando estes valores encontrados e pela dinâmica de $\mathrm{K}$ no solo podemos levantar a hipótese de uma adubação de manutenção na cultura ou dividir a correção de forma a se usar metade na cultura de inverno e metade na cultura de verão ou o quanto mais próxima a implantação desta, ao invés de se fazer uma adubação de correção de solo em uma única aplicação.

Tabela 5 - Faixas de interpretação e distribuição percentual dos teores de potássio, na amostragem e reamostragem ( 0 $15 \mathrm{~cm}$ ) para a classe de solo com CTC pH 7,0 entre 10,1 e 15. Santo Ângelo - RS, 2014

\begin{tabular}{llll}
\hline $\begin{array}{c}\text { Faixa de } \\
\text { interpretação }\end{array}$ & Teor de potássio & $\begin{array}{l}\text { Amostragem(2011) } \\
\text { \% }\end{array}$ & $\begin{array}{l}\text { Reamostragem(2014) } \\
\text { \% }\end{array}$ \\
\hline Muito baixo & & 0 & 0 \\
Baixo & 40 & 0 & 10 \\
Médio & $81-80$ & 0 & 29 \\
Alto & $121-240$ & 100 & 61 \\
Muito Alto & $>240$ & 0 & 0 \\
\hline
\end{tabular}

Fonte: Arquivo do Autor

Analisando os valores demonstrados na Tabela 6 a seguir, podemos observar uma redução de $43 \%$ no uso de Calcário, o que representou uma economia de $\mathrm{R} \$$ $70,00 /$ ha, equivalente a $\mathrm{R} \$ 4.035,00$ na área total das 58ha.Também observou-se na mesma, pelos valores da receita bruta um acréscimo na área manejada com AP de $\mathrm{R} \$ 675,00 /$ ha por ano em relação a área testemunha.

Observou-se na (Tabela 5) que os aumentos de produtividade média durante os dois anos seguintes a grande estiagem de cinco meses no verão de 2011/12, foram para as culturas de soja e trigo respectivamente, de 19 e $28 \%$.

Apesar de que os benefícios com a adoção de técnica de agricultura de precisão em termos de ganhos de produtividade e/ou redução de custos estarem relacionados à variabilidade encontrada nas lavouras e ao nível de acerto que tecnicamente podem ser obtidos nas diferentes fases do processo, o estudo mostra que o retorno econômico ao produtor foi positivo de $22 \%$. 
Tabela 6 - Avaliação econômica de áreas conduzidas em agricultura de precisão (AP) comparativamente a forma convencional (Testemunha), nas áreas em avaliação nos anos de 2012 a 2014. Santo Ângelo - RS. 2014.

\begin{tabular}{|c|c|c|}
\hline & AP (58 ha ) & Testemunha ( 57 ha ) \\
\hline Média produtividade de soja sc/ha & 43 & 36 \\
\hline Média produtividade de trigo $\mathrm{sc} / \mathrm{ha}$ & 58 & 45 \\
\hline Equipamento (TV ) & 3016,00 & 0 \\
\hline Calcário & 5245,00 & 9120,00 \\
\hline Cloreto de Potássio & 2940,00 & 0 \\
\hline Gasto de combustível aplicações & 137,00 & 0 \\
\hline Equipamento ( TV ) R\$/ha & 52,00 & 0 \\
\hline Serviço (TV ) - R\$/ha & 2900,00 & 0 \\
\hline Total $\mathbf{R} \$ / \mathbf{h a} / \mathbf{a n o}$ & 82,00 & 54,00 \\
\hline Receita Bruta total $\mathbf{R} \$ / \mathbf{h a} / \mathbf{a n o}$ & 3600,00 & 2925,00 \\
\hline Saldo Operacional/ha/ano & 3518,00 & 2871,00 \\
\hline Saldo Operacional \% & 122,00 & 100 \\
\hline
\end{tabular}

Fonte: Arquivo do autor

\section{CONCLUSÕES}

Foram aplicadas 65,5 toneladas de Calcário dolomítico, uma redução de $43 \%$ em relação a um total de 116 toneladas, equivalente a 2,0 toneladas por hectare normalmente usadas, com acréscimo de produtividade 19 e $28 \%$ nas culturas da soja e trigo em relação à área testemunha sem AP.

Constatou-se que o efeito da calagem foi inferior a três anos e que houve uma redução CV\% dos valores, com uma pequena redução da heterogeneidade horizontal dos valores de $\mathrm{pH}$ do solo desta área em estudo.

Apesar de que o estudo ter sido realizado em uma área com fertilidade já construída para o Fósforo e de que alguns resultados não terem sido os esperados, o sistema de AP mostrou um retorno econômico de $22 \%$ em relação a uma área testemunha, sem AP.

$\mathrm{O}$ estudo realizado mostrou viabilidade econômica na compra de um equipamento de taxa variada, parcelado em 10 anos ao juro de $6,5 \%$ ao ano, ao invés de contratar uma empresa terceirizada.

Os estudos realizados e a posse de informações tão relevantes sobre o crescimento da população e a grande demanda de alimentos que serão necessários em nível global, juntamente com ferramentas tecnológicas que estão surgindo e propondo ganhos em produtividade e rentabilidade, confirmam esta tecnologia como mais uma ferramenta de trabalho que vem a trazer maior rentabilidade ao produtor rural e maior produção de alimentos que a população mundial necessita.

Assim sendo, confirma-se a importância da conservação e melhoria da fertilidade do solo como um importante recurso para o aumento da rentabilidade das propriedades rurais.

Devido ao fato da redução dos valores de média, máxima e não aumento dos valores de mínimas do $\mathrm{pH}$ do solo na reamostragem em 2014 , levanta-se a hipótese de se aumentar a porcentagem da dose da fórmula da Necessidade de Calagem.

Sugere-se mais cuidado na forma de se fazer a correção de potássio, adotando medidas que possam reduzir perdas, tais como aplicação na cultura implantada ou o mais próximo possível da implantação desta, como também parcelamento da dose de correção, aplicando-se a metade na cultura de inverno e metade da cultura de verão.

\section{REFERÊNCIAS}

ALBUQUERQUE, J.A.;REINERT, D.J.;FIORIN, L.E. Variabilidade de solo e plantas em podzólico vermelho-amarelo. Revista Brasileira de Ciência do solo, v.20, n.1, p.151-157, 1996.

AMADO, T.J.C., PONTELLI, C.B., SANTI, A.L., VIANA, J.M., SULZBACH, L.A.D.S. Variabilidade espacial e temporal da produtividade de culturas sob sistema de plantio direto.Pesquisa Agropecuária Brasileira,2007, vol.42(8), p.1101. Disponível em: <http://www.periodicos.capes.gov.br >. Acesso em 02 de fevereiro de 2014.

AMADO, T.J.C., SANTI, A.L. Agricultura de precisão aplicada ao aprimoramento do manejo do solo. In: FIORIN, J.E., ed. Manejo da fertilidade do solo no sistema plantio direto. Passo Fundo: Berthier, 2007.

BELLÉ, G.L. Agricultura de Precisão:Manejo da Fertilidade com Aplicação a Taxa Variada de Fertilizantes e sua Relação com a Produtividade das Culturas. Santa Maria: UFSM, 2009.

BLACKMORE et al. ( 1994 ) apud TCHIEDEL, M., FERREIRA, M.F. Introdução à Agricultura de Precisão: Conceitos e Vantagens. In: Ciência Rural vol.32.no1. Santa Maria.2002.

CARVALHO, I. F. Agricultura de precisão:Boletim Técnico. Brasília: Mapa/ACS. 2011.

CAMPO, P. do. Agricultura de precisão. Inovações do campo.Piracicaba. 2000a. Disponível em: <http://www1.portaldocampo.com.br/inovacoes/agric _precisao.htm> . Acesso em 22 de julho de 2013.

CORÁ, J. E., BERALDO, J. M. G. Variabilidade espacial de atributos do solo antes e após a calagem e fosfatagem em doses variadas na cultura da cana-deaçucar. Revista Engenharia Agrícola, v.26, n.2, p. 374-387, 2006.

COSTA, C. C. DA. G., MARTINS, J. M. Impacto da Agricultura de Precisão na Economia Brasileira. (2011) Disponível em: <http://www.macroprograma1.cnptia.embrapa.br/rede 
ap2/laboratorio-nacional-de-agricultura-deprecisao/livro-agricultura-de-precisao-um-novoolhar/5.3>. Acesso em 3 de Agosto de 2013.

DEBIASI, H., FRANCHINI, J.C. Atributos físicos de solo e produtividade da soja em sistema de integração lavoura-pecuária com braquiária e soja. In: Ciência Rural, Santa Maria, v.42, n.7,p.1180-1186, Jul.2012.

FIORIN, J. E., COCCO, K.L.T., AMADO, T.J.C., WYZYKOWSKI, T., LORENZONI, J., SILVA Jr, V.L.R., HAUSCHILD, F.E.G. Viabilidade técnica e econômica da agricultura de precisão no Sistema Cooperativo do Rio Grande do Sul. BOLETIM TÉCNICO CCGL TEC. Cruz Alta: CCGL TEC, 2011.

FRANCHINI, J.C. et al. Manejo de solo para redução de perdas da produtividade pela seca. EMPRAPA SOJA. Londrina,PR.2009.

GENRO JUNIOR, S.A. et al. Atributos físicos de um latossolo vermelho e produtividade cultura cultivados em sucessão e rotação. In: Ciência Rural, Santa Maria,v.39,n.1,p. 65-73, jan-fev, 2009.

LEMAINSKI, C.L. Agricultua de Precisão aplicada a áreas irrigadas com pivot central no RS. Universidade Federal de Santa Maria. 2007.

MAGALHÃES, R. Agricultura de Precisão mostra efeitos em laranjais. Disponível em:

<http://www.usp.br/agen/?p=133563> Acesso em 3 de Agosto de 2013.

MENEGATTI, L.A.A., MOLIN, J.P., GÓES, S.L., KORNDORFER, G.H., SOARES, R.A.B., LIMA,

E.A. Benefícios Econômicos e Agronômicos da Adoção da Agricultura de Precisão em Usinas de Cana-de-Açucar. ESALQ/USP. Congresso Brasileiro de Agricultura de Precisão. São Pedro, SP Disponível em: <http://www.ler.esalq.usp.br/download/TEC\%202 006.07.pdf $>$ Acesso em 3 de Agosto de 2013.
MOLIN (2002) apud HAUSCHLID, F.E.G. Técnicas de Agricultura de Precisão para definição de zonas de manejo de solo. Dissertação (Agricultura de Precisão) PPGAP UFSM. 2013.

MOLIN, J. P. Definição de unidades de manejo a partir de mapas de produtividade. Disponível em:<http://www.leb.esalq.usp.br/molin/definicao.pdf $>$ . Acesso em: 15 de Abril de 2013.

MUTEIA, H. Palestra no Rural Tecnoshow, O papel dos países emergentes no combate a fome. Disponível em: <https://www.fao.org.br/FAOddma.asp Organização da Nações Unidas para Alimentação e Agricultura> Acesso em 2 de fevereiro de 2014.

PES, L.Z., AMADO, T.J.C., DELLAMEA, R.B.C., LEMAINSKI, M.C., BELLÉ, G.L., PIZZUTI, L., SCHENATO, L. F., FÜLBER, R. Projeto Aquarius/Cotrijal - Pólo de Agricultura de Precisão na Região Alto Jacuí - RS. In: $2^{\circ}$ Congresso Brasileiro de Agricultura de Agricultura de precisãoESALQ/USP. São Pedro - SP, 2006.

SANTI, A.L., FIORIN, J.E., COCCO, K.L.T., CHERUBIN, M.R., EITELWEIN, M.T., AMADO, T.J.C., HAUSCHILD, F.E.G. Distribuição horizontal e vertical de fósforo e potássio em área manejada com ferramentas de Agricultura de Precisão. In: Revista Plantio Direto. Maio/Junho-2012. p. 18-25.

VARGAS, I.C. Agricultura de Precisão - Nova Tecnologia Permite Conhecer Cada Metro Quadrado da Lavoura. Disponível em: <http://www.webrural.com.br/webrural/artigos/tecnol ogia/ap/ap.htm>Acesso em 10 de fevereiro de 2015.

VIACHESLAV \& MOLIN ( 2006 ) apud HAUSCHLID, F.E.G. Técnicas de Agricultura de Precisão para definição de zonas de manejo de solo. Dissertação (Agricultura de Precisão) PPGAP UFSM. 2013 